\title{
Poluição Sonora e Direito ao Sossego
}

\section{Sound Pollution and Right to be quiet}

\author{
Rodrigo Pereira Moreira ${ }^{1}$ \\ Jaquiel Robinson Hammes da Fonseca ${ }^{2}$
}

\begin{abstract}
Resumo: O meio ambiente como direito fundamental de terceira dimensão não está totalmente dissociado dos direitos individuais de primeira dimensão. Assim, a emissão de ruídos de forma desproporcional (poluição sonora) causa um dano ambiental, mas também pode ocasionar a violação do direito ao sossego. Apesar de estar localizado no direito de vizinhança, o direito ao sossego é um direito da personalidade com oponibilidade erga omnes e garante ao seu titular o respeito às suas decisões pessoais sobre as impressões sensitivas que devem ou não chegar aos seus sentidos. O presente artigo possui como objetivo analisar a relação entre proteção do meio ambiente, poluição sonora e tutela do direito ao sossego. Para tanto, utilizar-se-á o método dedutivo com procedimento técnico de pesquisa bibliográfica. Dessa maneira, chega-se à conclusão que a poluição sonora também é causadora de dano a direito da personalidade (direito ao sossego), cuja tutela repressiva é a reparação civil por meio dos danos morais.
\end{abstract}

Palavras-chave: Meio ambiente artificial; Vizinhança; Danos morais.

\begin{abstract}
The environment as a fundamental right of the third dimension is not totally dissociated from the individual rights of the first dimension. So, noise emission disproportionately (noise pollution) causes environmental damage, but can also lead to violation of the right to be quiet. Despite being located in the right of neighborhood, the right to be quiet is a right of the personality with erga omnes enforceability and guarantees to the holder the respect to their personal decisions on the sensory impressions that should or should not reach their senses. This article aims to analyze the relationship between environmental protection, noise pollution and protection of the right to be quiet. To do so, the deductive method will be used with a technical bibliographic search procedure. Thus, it is concluded that noise pollution also causes harm to the right of the personality (right to be quiet), whose repressive tutelage is civil reparation through moral damages.
\end{abstract}

Keywords: Artificial environment; Neighborhood; Moral damages.

\section{Introdução}

Em uma sociedade pós-industrial os danos indenizáveis aumentaram significativamente. Com o crescimento das grandes cidades, um grave

\footnotetext{
${ }^{1}$ Professor de Direito da Universidade Estadual de Goiás (UEG) e do Instituto Luterano de Ensino Superior de Itumbiara/GO. Mestre em Direito pela UFU/MG.

2 Coordenador do Curso de Direito do Instituto Luterano de Ensino Superior de Itumbiara/GO. Mestre em Direito pela Universidade de Marília/SP (UNIMAR).
} 
problema ambiental diz respeito à poluição sonora. Este tipo de poluição se caracteriza pela produção de ruídos acima do tolerável para o meio ambiente artificial. Por outro lado, também é possível que o dano causado pelo excesso de ruídos possa afetar pessoais individualizadas. Dessa maneira, o presente artigo busca responder ao seguinte questionamento: a poluição sonora pode causar simultaneamente danos difusos e individuais?

Como hipótese tem-se que a poluição sonora afeta tanto interesses difusos quanto interesses individuais, como no caso de violação do direito ao sossego, espécie de direito da personalidade. O tratamento preventivo deve ter preferência, mas uma vez concretizado o dano, este deve ser reparado por meio de indenização por danos morais (coletivos e individuais).

O objetivo geral do presente artigo é analisar a inter-relação existente entre a proteção ambiental (difusa e coletiva) e a proteção do direito ao sossego (individual) no tocante aos prejuízos causados pela poluição sonora. Os objetivos específicos são: (i) analisar a relação entre poluição sonora e proteção ao meio ambiente artificial; (ii) estudar a configuração do direito ao sossego como direito da personalidade; (iii) verificar os instrumentos de prevenção e repressão, coletivos e individuais, ao dano causado pela poluição sonora. Para tanto, utilizar-se-á o método dedutivo com procedimento técnico de pesquisa bibliográfica.

Assim, num primeiro momento, observar-se-á a proteção constitucional ao meio ambiente sadio e equilibrado e a caracterização da poluição sonora como violação (dano) do meio ambiente artificial e urbano. Por conseguinte, será estudado o direito ao sossego em conjunto com a teoria dos direitos da personalidade, analisando a sua conexão com o direito de vizinhança e a tutela individual da dignidade e do livre desenvolvimento da personalidade da pessoa humana.

Por fim, abordaremos os possíveis instrumentos de direitos difusos e individuais na tutela do meio ambiente e do direito ao sossego frente ao 


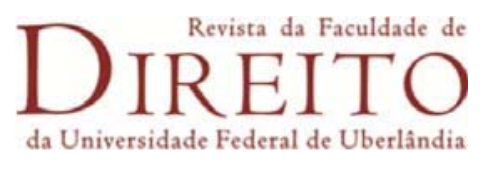

dano causado pela poluição. Neste ponto serão abordadas as técnicas de proteção preventiva e repressiva do dano causado.

\section{Meio Ambiente e Poluição Sonora}

Para delimitar a amplitude da proteção ambiental é preciso compreender o significado de meio ambiente, sua classificação e relação com a Constituição Federal (CF) de 1988. Após estas explicações iniciais, será possível entender a relação entre a proteção ambiental nas cidades e a poluição sonora.

A expressão meio ambiente é um pleonasmo, haja vista que meio e ambiente são palavras sinônimas (LEITE; AYALA, 2011, p. 73). Nas palavras de Aguinaldo Alemar (2013, p. 20) meio ambiente é "o locus no qual os fatores bióticos e abióticos se organizam, mediante contínuas interrelações, de modo a permitir a perpetuidade da existência planetária.”

Uma abordagem do meio ambiente deve englobar a noção de pessoa humana (LEITE; AYALA, 2011, p. 75). Neste ponto existem três formas de pensar a relação da pessoa com o meio ambiente: (i) uma visão antropocêntrica de meio ambiente, que envolve um direito subjetivo que as pessoas têm sobre um meio ambiente; (ii) uma visão geocêntrica, que visa à tutela do meio ambiente de forma coletiva (LORENZETTI, 2010, p. 25), como um bem em si mesmo; e (iii) uma visão antropocêntrica alargada, que envolve o homem em relação com a natureza, defendendo que não existe uma dominação do homem sobre o meio ambiente, mas uma relação pacífica entre eles (LEITE; AYALA, 2011, p. 76). ${ }^{3}$

\footnotetext{
${ }^{3}$ Nas palavras dos autores: "[...] a perspectiva antropocêntrica alargada propõe não uma restritiva visão de que o homem tutela o meio ambiente única e exclusivamente para proteger a capacidade de aproveitamento deste, considerando precipuamente satisfazer as necessidades individuais dos consumidores, em uma definição economicocêntrica. Com efeito, esta proposta vista, de maneira adversa, a abranger também a tutela do meio ambiente, independentemente da sua utilidade direta, e busca a preservação da capacidade funcional do patrimônio natural, com ideais éticos de colaboração e interação" (LEITE; AYALA, 2011, p. 79-80).
} 
Levando em consideração o personalismo jurídico reconhecido na Constituição Federal pelo princípio da dignidade da pessoa humana, entende-se que o meio ambiente deve ser entendido em sua relação com o ser humano, prevalecendo a ideia de uma visão antropocêntrica alargada do direito fundamental ao meio ambiente.

Ademais, é preciso fazer uma diferenciação entre a proteção do meio ambiente como um macrobem e como microbens. A noção como macrobem envolve o conteúdo do meio ambiente entendido como um sistema, ou seja, a interação de todas as suas partes, enquanto a abordagem como microbens envolve a consideração de seus subsistemas de forma isolada, apresentando estes uma relação externa com o macrobem (LORENZETTI, 2010, p. 26). Dentre esses subsistemas têm-se a fauna, a flora, meio ambiente artificial, patrimônio cultural, etc.

Nas palavras de José Rubens Morato Leite e Patryck Ayala (2011, p. 85):

[...] visualiza-se o meio ambiente como um macrobem, que além de bem incorpóreo e imaterial se configura como bem de uso comum do povo. Isso significa que o proprietário, seja ele público ou particular, não poderá dispor da qualidade do meio ambiente ecologicamente equilibrado, devido à previsão constitucional, considerando-o macrobem de todos.

Do ponto de vista didático e com fundamento na Constituição Federal pode-se classificar o meio ambiente em: (i) meio ambiente cultural (Arts. 215, 216 e 225); (ii) meio ambiente artificial (Arts. 182, 183 e 225); (iii) meio ambiente do trabalho (Art. 200, inc. VIII, Art. $7^{\circ}$, inc. XXII e Art. 225); (iv) meio ambiente natural (Art. 225) e (v) patrimônio genético (Art. 225, parágrafo $1^{\circ}$, inc. II e V) (BRASIL, 1988).

Quanto ao meio ambiente cultural (i), é preciso entender que os bens da natureza não são apenas materiais, mas também imateriais, tanto individualmente quanto coletivamente. Neste diapasão, o meio ambiente cultural refere-se à identidade, memória dos diferentes grupos formadores 
da sociedade, modos de viver, criações artísticas, documentos, edificações históricas, etc. (FIORILLO, 2007, p. 56).

O meio ambiente artificial (ii) está relacionado ao bem-estar das pessoas que vivem nas cidades. A qualidade de vida nas cidades é entendida como um bem metaindividual protegida por esta espécie de meio ambiente (FIORILLO, 2007, p. 62). Isso se refere a temas importantes como a segurança, o transporte, a poluição visual e sonora, cujo enfoque será concedido nesta pesquisa.

O terceiro, meio ambiente do trabalho (iii), tutela em especial a saúde humana de forma preventiva no local em que cada pessoa trabalha (FIORILLO, 2007, p. 62). O meio ambiente natural (iv), por sua vez,

[t]em proteção ambiental constitucional estabelecida em decorrência do que determina o art. 225 da Carta da República, que assegura não só a tutela jurídica da fauna e da flora em face dos princípios fundamentais constitucionais e demais dispositivos aplicáveis (o que inclui evidentemente a proteção de seus respectivos patrimônios genéticos, como já dissemos), como dos demais recursos ambientais protegidos constitucionalmente, a saber: a atmosfera (mistura de gases chamada de art, composta fundamentalmente de Nitrogênio e Oxigênio), as águas (interiores, superficiais e subterrâneas), o solo, o subsolo, bem como os elementos da biosfera (hidrosfera, troposfera e litosfera, inclusive organismos metabolicamente ativos) (FIORILLO, 2007, p. 63-64).

Por fim, o patrimônio genético (v), que merece tutela jurídica por vincular-se à proteção da vida face aos avanços da engenharia genética, protegendo o material genético na construção de seres vivos (FIORILLO, 2007, p. 53).

Neste diapasão, é imperioso constatar que a proteção ambiental é ampla e não engloba apenas o meio ambiente natural. As cidades - como meio ambiente artificial - também gozam de tutela jurídica com o objetivo de manter uma boa qualidade de vida. Como observado, esta tutela começa na Constituição Federal de 1988, razão pela qual passa-se a analisar os fundamentos constitucionais do meio ambiente. 


\subsection{Proteção Constitucional do Meio Ambiente}

Em termos constitucionais, primeiramente faz-se necessário verificar a configuração da proteção ambiental como direito fundamental, na medida em que a tutela do meio ambiente equilibrado assume feições específicas dentro do próprio sistema constitucional de direitos fundamentais de terceira dimensão.

Assim, a nova ordem constitucional, instaurada em 1988, deixa transparente a sua preocupação ambiental. Tanto que atribuiu um capítulo específico para o tema, como um elemento da "Ordem Social", elevando-o inclusive como direito fundamental da pessoa humana, quando dispõe no Art. 225 que "todos têm direito ao meio ambiente ecologicamente equilibrado [...]”. Nas palavras de José Afonso da Silva:

A proteção ambiental, abrangendo a preservação da Natureza em todos os seus elementos essenciais à vida humana e à manutenção do equilíbrio ecológico, visa tutelar a qualidade do meio ambiente em função da qualidade da vida, como uma forma de direito fundamental da pessoa humana (SILVA, 2009, p. 58).

A percepção pelo constituinte da necessidade de um ambiente sadio como direito fundamental é correlato lógico do fundamento constitucional que assegura a todos uma vida digna, o qual só é possível alcançar por via da garantia do bem-estar, que compreende indubitavelmente a relação harmoniosa entre homem e ambiente. No entanto, para o ordenamento jurídico assumir essa proteção fundamental, fora necessário primeiro desvincular a ideia de que a preocupação ambiental tão-somente se atrelava aos campos da Moral e da Economia.

Nesse norte, Vicente Ráo (1997, p. 577) ressalta o papel social nessa transformação:

[...] em sua origem, essa regra não possuía um conteúdo próprio, confundindo-se, como se confundia, com as regras morais e econômicas; mas, quando da consciência social do grupo a reputou necessária e passou a reclamar sua aplicação por meios coercitivos, então e daí por diante transformou-se em regra de direito. 
Importante destacar que a alteração da consciência socioambiental não constituiu uma ação imediata e muito menos se encontra findada; pelo contrário: é lenta e gradual, tendo muito ainda por percorrer, mas há de se destacar o grande avanço já realizado, em especial a percepção de que o Universo não é submetido apenas à realização das necessidades do homem, bem como que a degradação ambiental poderá representar a extinção da espécie humana.

Para essa alteração cultural e educacional foram relevantes as várias reuniões, convenções e manifestações ocorridas no cenário internacional. Entre elas a "Conferência das Nações Unidas sobre o Meio Ambiente Humano", realizada na cidade de Estocolmo [Suécia] em 1972, sendo que para o presente tema, ressalta-se o princípio 1 da "Declaração de Estocolmo sobre o Ambiente Humano", cujo texto já defendia a existência de um direito fundamental ao ambiente de qualidade.

Princípio $1-\mathrm{O}$ homem tem o direito fundamental à liberdade, à
igualdade e ao desfrute de condições de vida adequadas, em um
meio ambiente de qualidade tal que lhe permita levar uma vida
digna, gozar de bem-estar e é portador solene da obrigação de
proteger e melhorar o meio ambiente, para as gerações presentes e
futuras. ${ }^{4}$

Nesse contexto, ainda em 1972, foi realizada em Paris a XVII Sessão da "Conferência Geral da Organização das Nações Unidas para a Educação, a Ciência e a Cultura", que resultou na "Convenção Relativa à Proteção do Patrimônio Mundial, Cultural e Natural”, cujo texto integrou o ordenamento brasileiro por via do Decreto n. 80.978 de 12 de dezembro de 1977. Esse texto é considerado por Fábio Konder Comparato (2001, p. 381) como a primeira norma a admitir a existência de um direito da humanidade.

Após a "Conferência de Estocolmo", inúmeros acordos, reuniões e convenções foram realizados com o intuito de proteger o meio ambiente. Destaque para a Conferência da Organização das Nações Unidas [ONU]

4 A Declaração de Estocolmo sobre o Meio Ambiente está disponível em: $<$ http://www.scribd.com/full/6305358?access_key=key-mp8k7oq8evcz1gpag57>, acesso em 30 mai. 2019. 
realizada no Rio de Janeiro em 1992, onde o direito fundamental ao ambiente de qualidade foi reafirmado pela "Declaração do Rio sobre Meio Ambiente e Desenvolvimento" (MILARÉ, 2009, p. 818).

O direito fundamental ao "meio ambiente equilibrado", utilizando expressão adotada pelo constituinte brasileiro, configura direito supraindividual, que transcende a individualidade da pessoa e é diretamente relacionada aos direitos de fraternidade e solidariedade, denominados direitos de terceira dimensão (BONAVIDES, 1994, p. 522).

Hamilton Alonso Júnior (2006, p. 39-40) estabelece válida a relação entre a necessidade de preservação ambiental e a sua percepção humanística, esta decorrente da deflagração de solidariedade que se expandiu pelo planeta, em especial pelos movimentos e convenções internacionalmente realizadas, bem como a percepção de que tal direito é inerente à natureza humana.

Por conseguinte, assegura Alonso Júnior (2006, p. 39-40) que a identificação do ambiente sadio como direito fundamental possui amparo material e formal, não necessitando, inclusive, que para tal adjetivação necessite estar previsto como tal, seja na Constituição ou em outro texto legal. Os direitos fundamentais materiais, por sua vez, são aqueles não previstos no texto constitucional, ou, se previstos, não se encontram no título II da Constituição, mas que por serem equiparáveis, em seu objeto e importância, aos direitos formalmente constitucionais, também são considerados direitos fundamentais face à norma de fattispecie aberta (CANOTILHO, 2003, p. 403-404) $)^{5}$.

Dessa maneira, a fundamentalidade material decorre do fato de que os direitos fundamentais fazem parte da estrutura básica do Estado e da

\footnotetext{
${ }^{5}$ Segundo Vieira de Andrade (2012, p. 74-75): “[...] isso significa que o caráter fundamental dos direitos não corresponde à sua previsão ou especificação no texto constitucional e que se torna necessário um critério de substância para determinar o âmbito desta matéria: só assim se poderão encontrar, nas leis e nas normas internacionais e mesmo na parte organizatória do texto constitucional, os direitos daquela espécie. Haverá, assim, direitos fundamentais em sentido material que não o são formalmente, porque não estão incluídos no catálogo constitucional".
} 
sociedade e são, portanto, constitutivos da Constituição material, por intermédio do Art. $5^{\circ}$, parágrafo $2^{\circ}$ da $\mathrm{CF}$, que demonstra a insuficiência apenas do conceito formal. É a análise do conteúdo do direito que poderá identificá-lo como fundamental ou não, a depender se este contém decisões fundamentais para a estrutura do Estado ou da sociedade face à posição ocupada pela pessoa humana no sistema jurídico brasileiro (SARLET, 2012, p. 75).

Por conseguinte, não há como negar a fundamentalidade do ambiente sadio, tendo em vista que ele se coaduna perfeitamente com os fundamentos propostos pela Constituição Federal, em especial o fato de ser elemento indissociável à dignidade da pessoa humana e à cidadania, pois sem um ambiente saudável não é possível o desfrute desses direitos.

No aspecto formal, também não assistem dúvidas quanto à identificação do ambiente sadio como fundamental, haja vista que a Constituição da República Federativa do Brasil de 1988, em seu Art. 5º parágrafo $2^{\circ}$, estabelece que "os direitos e garantias expressos nesta Constituição Federal não excluem outros decorrentes do regime e dos princípios por ela adotados, ou dos tratados internacionais em que a República Federativa do Brasil seja parte", inclusive com aplicação imediata, conforme o parágrafo $1^{\circ}$ do mesmo Art. $5^{\circ}$ (ALONSO JÚNIOR, 2006, p. 41-43; BRASIL, 1988).

Assim, não sendo suficiente o fato de a existência de um ambiente sadio se enquadrar aos princípios previstos na Constituição, o Brasil também aderiu, em 24 de janeiro de 1992, ao Pacto Internacional sobre Direitos Econômicos, Sociais e Culturais. Esse acordo passou a vigorar no País a partir de 24 de abril de 1992, em face de edição do Decreto n. 591, de 6 de julho de 1992, o qual assegura às pessoas o mais elevado nível de saúde física e mental, devendo para isso, entre outras medidas, o Estado melhorar as condições ambientais (ALONSO JÚNIOR, 2006, p. 41-43). 
Identificada a fundamentalidade do ambiente sadio, resta verificar o tratamento constitucional conferido a esse direito fundamental. Em seu Art. 225, caput, a Constituição, inicialmente, cuidou de versar sobre o bem a ser tutelado: "o meio ambiente ecologicamente equilibrado" é aquele ambiente desprovido de poluição, não lesivo à vida humana, cuja titularidade pertence a todas as pessoas humanas (BRASIL, 1988).

O Art. 225 da Constituição Federal apresenta-se como um contraponto, tendo em vista que ao mesmo tempo em que todos têm direito a um ambiente sadio, todos possuem também o dever de protegê-lo, pois o bem tutelado é de "uso comum do povo", de natureza difusa e representa um direito intergeracional (BRASIL, 1988). O meio ambiente deve ser preservado para as gerações futuras, em face do princípio da solidariedade entre as gerações; a norma ainda impõe, especialmente ao Estado, um dever de proteção, atribuindo-lhe inclusive responsabilidade objetiva no caso da ocorrência de dano ambiental.

Nesse diapasão, impõe-se acrescentar o conceito de meio ambiente formulado pelo Ministro Celso de Mello, quando do julgamento do Mandado de Segurança n. ${ }^{\circ}$ 22.164-0-SP,

[...] como um típico direito de terceira geração que assiste, de modo subjetivamente indeterminado, a todo o gênero humano, circunstância essa que justifica a especial obrigação - que incumbe ao Estado e à própria coletividade - de defendê-lo e de preservá-lo em benefício das presentes e futuras gerações (BRASIL, 1995).

A proteção ambiental nessa Nova Ordem é de imensa magnitude; não se limita a ações isoladas, e seus diversos mecanismos e ações estão direcionados ao alcance do bem-estar social, possuindo, inclusive, o condão de interferir diretamente nas atividades econômicas, bem como na propriedade privada.

Assumido o meio ambiente sadio com direito fundamental, desse modo, indisponível, pois também está direcionado ao atendimento das gerações futuras, observa-se que o legislador constituinte, ao versar sobre a 
proteção ambiental, estabeleceu seus contornos gerais, conforme disposto no caput; todavia, foi além, haja vista que prescreveu também instrumentos a serem observados pelo Poder Público e pelos particulares, a fim de efetivar a concretização desse direito fundamental, descritos nos parágrafos do Art. 225 da Constituição.

Nesse sentido, José Afonso da Silva (2009, p. 52) descreve o Art. 225 de forma sintética, visualizando três grupos distintos de normas: o primeiro, localizado no caput, o autor identifica como "norma-princípio", "norma matriz", aquela que identifica o direito ao ambiente sadio; por segundo, são as "normas instrumentos", responsáveis por garantir a concretude do direito, cujo conteúdo é direcionado exclusivamente ao Poder Público; por fim, visualizam-se as "determinações particulares" que, em face de seu relevante interesse ecológico, merecem cuidados especiais a fim de adequação ao princípio maior estabelecido no caput.

Diante da proteção especial conferida ao ambiente pela Constituição, cabe ao legislador infraconstitucional, ao executor das políticas públicas de todos os âmbitos de atuação, bem como a toda a coletividade adotar as medidas capazes de assegurar a preservação ambiental para "as presentes e futuras gerações”, pois o ambiente saudável constitui elemento indissociável à dignidade da pessoa humana, em face do bem-estar que proporciona. Por isso a necessidade de estudar as características da poluição sonora e suas formas de tutela preventiva e repressiva no sistema jurídico brasileiro.

\subsection{Poluição Sonora}

A poluição sonora possui relação direta com a proteção ambiental, visto que, como ressaltado anteriormente, o meio ambiente não se limita a fauna e flora, como comumente conhecido; dentre o seu amplo campo de atuação, tem-se também o dever de proteção ao ambiente artificial, diretamente relacionado ao bem-estar das pessoas no seu viver nas cidades. 


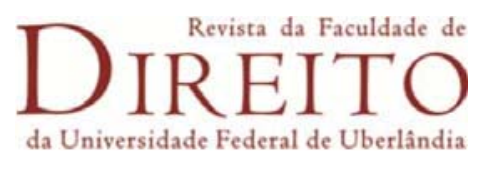

Neste sentido, difícil não falar de poluição sonora em se tratando de cidades, que certamente, prejudica o bem-estar do ser humano.

O conceito de poluição está inserido na Lei Federal n. 6.938 de 19816, que versa sobre a Política Nacional do Meio Ambiente. O conceito atribui especial significado a ações que afetem a qualidade ambiental e "prejudiquem a saúde, a segurança e o bem-estar da população".

Não obstante a conceituação apresentada, é necessário identificar qual seria a poluição derivada da emissão sonora. Em primeira análise define-se que "som é o fenômeno da ciência natural consistente na emissão de ondas decorrente da vibração dos corpos em meio elástico" (FINK, 1999, p. 3). Indubitável que nem todo som consiste em ação poluidora, visto que, conforme a legislação, é necessário que o som produzido provoque riscos ou prejuízos à saúde ou ao bem-estar das pessoas. Desta forma, tem-se que a poluição sonora é aquela indesejável e prejudicial, conhecida por ruído (FINK, 1999, p.3), capaz de provocar danos às pessoas.

O dano é a lesão a interesse juridicamente protegido, ou melhor dizendo, a um interesse juridicamente não vedado pelo ordenamento. $\mathrm{O}$ dano ambiental, por sua vez, pode ser visto de duas maneiras: (i) uma alteração nociva, indesejável, que modifica de forma sensível o equilíbrio ambiental; (ii) uma modificação reflexa na saúde das pessoas ou em outros interesses (LEITE; AYALA, 2011, p. 94). Isso porque as ações podem ser lesivas ao meio ambiente, ou seja, afetar o macrobem ambiental, de titularidade coletiva e ainda como consequência, lesar direitos individuais, como a vida e a saúde das pessoas (LORENZETTI, 2010, p. 39).7

\footnotetext{
${ }^{6} C f$. Art $3^{\circ}$ - Para os fins previstos nesta Lei, entende-se por: III - poluição, a degradação da qualidade ambiental resultante de atividades que direta ou indiretamente: (a) prejudiquem a saúde, a segurança e o bem-estar da população; (b) criem condições adversas às atividades sociais e econômicas; (c) afetem desfavoravelmente a biota; (d) afetem as condições estéticas ou sanitárias do meio ambiente; (e) lancem matérias ou energia em desacordo com os padrões ambientais estabelecidos (BRASIL, 1981).

${ }_{7}$ Para o autor, o lesado pode pedir a indenização dos danos extrapatrimoniais individuais e coletivos no mesmo processo se for legitimado para isso, mas o tribunal deve ser competente para apreciar os dois pedidos (LORENZETTI, 2010, p. 45).
} 
Assim, o dano ambiental pode ser amplo, quando afetar os interesses difusos da coletividade ou pode ser reflexo (ricochete) quando o dano ambiental também produzir efeitos na seara jurídica individual de cada pessoa (direitos da personalidade) (LEITE; AYALA, 2011, p. 95). A poluição sonora, como o ruído urbano exagerado que atrapalha o bem-estar coletivo, encaixa-se como uma lesão ambiental em sentido amplo. Apesar dos efeitos da poluição sonora muitas vezes serem sentidos após larga exposição aos ruídos, isto não a descaracteriza como uma grave agressão ao meio ambiente artificial e com diversas consequências à integridade física e psíquica das pessoas (FRANGETTO, 2011, p. 753-755).

É óbvio que nas cidades em que vivemos atualmente não é qualquer tipo de ruído que consistirá em poluição sonora e dano ambiental. Segundo Flávia Fangetto, é necessário estabelecer padrões de admissibilidade para emissão de ruídos que levem em consideração critérios para o atual quadro urbano (FRANGETTO, 2011, p. 753-755). A Associação Brasileira de Normas Técnicas define o limite de decibéis aceitáveis - $\mathrm{dB}(\mathrm{A})$ - nos diversos ambientes de acordo com a sua NBR 10.151. Nesta norma consta os seguintes dados:

Tabela 1 - Nível de Critério de Avaliação para ambientes externos, em dB(A)

\begin{tabular}{|l|c|c|}
\hline \multicolumn{1}{|c|}{ Tipos de áreas } & Diurno & Noturno \\
\hline Áreas de sítios e fazendas & 40 & 35 \\
\hline Área estritamente residencial urbana ou de hospitais ou de escolas & 50 & 45 \\
\hline Área mista, predominantemente residencial & 55 & 50 \\
\hline Área mista, com vocação comercial e administrativa & 60 & 55 \\
\hline Área mista, com vocação recreacional & 65 & 55 \\
\hline Área predominantemente industrial & 70 & 60 \\
\hline
\end{tabular}

Fonte: FRANGETTO, 2011, p. 753-755.

Todavia, mesmo que determinada fonte de ruído observe os limites propostos pela norma, ainda haverá casos em que poderá ocorrer dano ambiental de acordo com determinado caso concreto que exija tratamento especial, como aquele determinado pela lei de zoneamento de cada município. 
Como medidas preventivas, é necessário o cuidado do Estado no momento de concessão do licenciamento das atividades, especialmente econômicas, haja vista que a sua concessão não indica que as práticas do estabelecimento não sejam lesivas ao meio ambiente ou à saúde pública. No momento da concessão também deveria ser exigido um estudo de impacto ambiental direcionado para o impacto sonoro e não apenas para o impacto sobre o meio ambiente natural (FRANGETTO, 2011, p. 766-767). Posteriormente é necessária uma fiscalização do poder público para a repressão deste tipo de dano ambiental.

O consentimento para o exercício da atividade, bem como a fiscalização a fim de que possa haver efetividade da norma e a concretização do direito ao meio ambiente sadio à sociedade se tornam indispensáveis, cujas atribuições deverão ser exercidas no âmbito das autoridades incumbidas para tal fim. Neste aspecto, atribui-se tamanha importância ao papel do Poder Executivo, por via do exercício do poder de polícia, prerrogativa capaz de reprimir a poluição sonora.

Ao Poder Executivo é conferido tipicamente o exercício da atribuição do poder de polícia, que consiste em "um instrumento conferido ao administrador que lhe permite condicionar, restringir, frenar o exercício de atividade, o uso e o gozo de bens e direitos dos particulares, em nome do interesse da coletividade" (MARINELA, 2017, p. 297).

Ao versar especialmente sobre o exercício de atividades que necessitam de consentimento prévio do Estado para sua atuação, destaca-se que as licenças concedidas não chegam a ser uma carta branca para que a pessoa provoque interferências inadmissíveis e intoleráveis no meio ambiente artificial, até porque a licença é atribuída em caráter precário e pode ser cassada a qualquer momento (ATHENIENSE, 2011, p. 3), quando da constatação de violação de regras impostas na própria licença e no ordenamento; para tanto, necessário que os órgãos públicos possuam estruturas fiscalizatórias efetivas, a fim de garantir o bem-estar social. 
Não obstante o controle das atividades econômicas por via da necessidade de atuação prévia e fiscalizatória do poder público, a poluição sonora também pode ser causada por ações oriundas de particulares, as quais não estão sujeitas ao controle prévio, o que todavia não afasta as autoridades públicas do dever de fiscalização e repressão às condutas nocivas ao sossego.

Neste mesmo diapasão, cita-se a atribuição do Ministério Público no controle das atividades poluidoras, frente à competência geral de proteção ao interesse público, quando a norma jurídica entender a relevância de sua defesa para a sociedade, especialmente em se tratando e direitos difusos e coletivos (FINK, 1999, p. 11).

Todavia, como já discorrido, o dano ambiental, dentre eles a poluição sonora, pode atingir direitos individuais (ruído provocado por morador que atinge somente o vizinho ao lado), individuais homogêneos (ruído de um bar que atinge um grupo limitado de pessoas), coletivos (ruído de bar que atinge a população do bairro, representado pela associação de moradores) ou difusos (ruído provocado por aeroporto situado no centro de uma cidade), situações que interferem na conduta do Ministério Público (FINK, 1999, p. 8).

Assim, diante das considerações apontadas nesta seção, não restam dúvidas quanto à necessidade da atuação dos órgãos públicos incumbidos da defesa da sadia qualidade de vida, direito este muitas vezes violado pela poluição sonora. Não obstante, a poluição sonora não pode ser tratada apenas no âmbito coletivo. Isso porque o excesso de ruídos também pode afetar pessoas individualizadas, violando direitos da personalidade.

\section{Direito Geral de Personalidade e Direito ao Sossego}

O direito ao sossego consiste em um direito da personalidade específico e derivado do chamado direito geral de personalidade. A cláusula 
geral de tutela da pessoa humana, com fundamento no Art. 12 do Código Civil e nos princípios constitucionais da dignidade da pessoa humana e do livre desenvolvimento da personalidade, permite que a doutrina e a jurisprudência identifiquem direitos da personalidade que não estejam tipificados no sistema jurídico brasileiro ou que estejam fora do capítulo específico dos direitos da personalidade.

Os direitos da personalidade são entendidos como aqueles direitos essenciais que compõem a medula da personalidade (CUPIS, 2008, p. 24), protegem os modos de ser da pessoa humana (PINTO, 1999, p. 87), sendo derivados e necessários para a realização de sua dignidade (GOMES, 1974, p. 178) e de seu livre desenvolvimento (ZANINI, 2011, p. 94). Sua base é constituída por situações jurídicas subjetivas existenciais (TEPEDINO, 2008, p. 52) que visam a proteção e promoção da integridade psicofísica e moral da pessoa.

A primeira teoria que reconhece os direitos da personalidade concerne à teoria do número fechado de direitos da personalidade. Extremamente influenciada pela doutrina positivista, para essa teoria somente seriam direitos da personalidade aqueles que o direito positivo reconhecesse como tais, pois a enumeração de direitos da personalidade seria taxativa.

A proteção da pessoa humana ficaria condicionada à tipificação de cada direito da personalidade específico na legislação de direito privado (GARCIA, 2007, p. 86), razão pela qual também constitui uma teoria pluralista, pois existiriam vários direitos da personalidade fragmentados (CANTALI, 2009, p. 77). Adriano de Cupis (2008, p. 27), por exemplo, afirma que todos os direitos subjetivos possuem seu fundamento no direito positivado, acompanhando aqui os direitos da personalidade.

A superação do entendimento do sistema jurídico como um sistema fechado começa com a proposta de Claus-Wilhelm Canaris (2008, p. 12-13). Sua teoria parte da constatação de que a ideia de sistema deve conter dois grandes elementos: a ordenação e a unidade. A ordenação exprime "um 
estado de coisas intrínseco racionalmente apreensível, isto é, fundado na realidade" enquanto a unidade visa "não permitir uma dispersão numa multitude de singularidades desconexas, antes devendo deixá-las reconduzir-se a uns quantos princípios fundamentais".

O papel do sistema é identificar e realizar a adequação de valores e a unidade interior do ordenamento jurídico (CANARIS, 2008, p. 23). Para este autor, levando em consideração esse papel de adequação valorativa e unidade interior, o sistema jurídico só pode ser concebido como uma ordem axiológica ou teleológica de princípios jurídicos gerais (CANARIS, 2008, p. 280). São os princípios gerais que garantem a unidade do sistema jurídico.

Claus-Wilhelm Canaris (2008, p. 281) indica que este tipo de sistema é aberto, pois existe uma incompletude do conhecimento jurídico e uma constante mutabilidade dos valores jurídicos que fundamentam o sistema ${ }^{8}$. Neste diapasão, Maria Helena Diniz (2009, p. 449-450) defende um sistema jurídico aberto, incompleto e que está sempre em relação com outros sistemas, podendo então ser um sistema lacunoso caso haja uma incongruência ou alteração entre eles.

Contribuem para a abertura do sistema: as cláusulas gerais, os conceitos jurídicos indeterminados e as enumerações exemplificativas. Isto acaba por eliminar o engessamento dos direitos da personalidade e ainda protege a pessoa humana de todas as ameaças que possam surgir contra a sua personalidade, surgindo o direito geral de personalidade.

O direito geral de personalidade é construído na Alemanha a partir da interpretação do direito ao livre desenvolvimento da personalidade e do princípio da dignidade da pessoa humana. O direito geral da personalidade protege os diferentes modos de desenvolvimento da pessoa subdividindo-se

\footnotetext{
8 No mesmo sentido está a lição de $\operatorname{Karl} \operatorname{Larenz}(2009$, p. 693) ao constatar que: "o sistema interno não é, como se depreende do que foi dito, um sistema fechado em si, mas um sistema 'aberto', no sentido de que são possíveis tanto mutações na espécie de jogo concertado dos princípios, do seu alcance e limitação recíproca, como também a descoberta de novos princípios; seja em virtude de alterações da legislação, seja em virtude de novos conhecimentos da ciência do Direito ou modificações na jurisprudência dos tribunais".
} 
em: (i) direito à autodeterminação; (ii) direito à autopreservação; (iii) direito à autoapresentação (PIEROTH; SCHLINK, 2012, p. 177).

A autodeterminação permite que a pessoa possa configurar a sua própria identidade, bem como assegura a liberdade de não ser afetado massivamente na formação e afirmação desta identidade. Alcança, portanto, a liberdade de profissão e as liberdades de escolha no âmbito da sexualidade (MARTINS, 2012, p. 49).

A autopreservação ou autoconservação garante ao particular a possibilidade de se resguardar e se proteger da sociedade. Abrange a proteção das informações pessoais por meio da privacidade e da imagem na sua dimensão defensiva (PIEROTH; SCHLINK, 2012, p. 178).

O terceiro desdobramento, da autoapresentação ou autoexposição, concerne ao direito da pessoa de se expor ao público da forma que escolher, englobando os direitos à imagem, à honra pessoal, à autodeterminação informativa e à voz (MARTINS, 2012, p. 50).

Não obstante a possibilidade desta sistematização do direito geral da personalidade, bem como outras formas de sistematização, o importante na sua configuração é a afirmação de uma tutela integral (proteção e promoção) da pessoa humana que começa a partir da concepção do nascituro e que perdura, em determinados casos, até após a morte do indivíduo.

O direito ao sossego, derivado do direito geral de personalidade, indica um estado de paz de espírito ligado à tranquilidade, uma ausência de perturbação, descanso. Ligado à saúde psicofísica da pessoa humana, ou seja, na proteção de sua integridade física e psíquica, o direito ao sossego pode ser classificado como um direito da personalidade.

Lívia T. da Silva Monte Alto (2012, p. 407) afirma que o direito ao sossego é o direito de estar em paz e tranquilidade, de ficar em um estado de descanso. Assim, o sossego pode ser enquadrado tanto pelo seu aspecto físico, relacionado à calmaria, ausência de agitação, descanso e repouso do 
corpo físico, quanto pelo seu aspecto psíquico ligado à tranquilidade, paz de espírito (LOUREIRO, 2001, p. 118) e higidez mental.

Segundo Loureiro (2001, p. 118-119), “tem o homem o direito básico, embora não ilimitado, de controlar impressões sensitivas vindas do exterior. Tais impressões sensitivas seriam o som, a luz, o cheiro, as sensações térmicas e imagens que chegam até nós. [...] Poderíamos falar, portanto, de um direito geral de respeito à decisão individual do que ouvir, ver, ler, ou do que sentir."

Este direito não é ilimitado porque em uma sociedade de massificação e concentração urbana como a nossa, não é possível que a pessoa consiga um sossego total. Assim, não é qualquer tipo de impressão sensitiva que afetará o direito ao sossego, mas aquelas que ultrapassem um determinado grau de tolerância, que fuja da normalidade da convivência humana (LOUREIRO, 2001, p. 119) na sociedade pós-industrial.

Nesse diapasão, o direito ao sossego determina o dever erga omnes de manter um ambiente sadio e propício para o livre desenvolvimento da personalidade do ser humano, respeitando as suas decisões no tocante às impressões sensitivas que a pessoa deseja ou não compartilhar.

\subsection{A vizinhança e o Direito ao Sossego}

À vizinhança corresponde o espaço em que uma pessoa, utilizando-se do seu direito de propriedade, pode afetar outra pessoa de forma prejudicial. Desta maneira, não é necessário que exista confrontação entre os imóveis para se encaixar no conceito de vizinhança.

O direito ao sossego é previsto no direito de vizinhança no Art. 1277 do Código Civil (Lei Federal n. 10.406 de 2002). ${ }^{9}$ O sossego do vizinho pode ser prejudicado não apenas pelo barulho (som), mas também pelo cheiro, luz

\footnotetext{
9 Art. 1.277. O proprietário ou o possuidor de um prédio tem o direito de fazer cessar as interferências prejudiciais à segurança, ao sossego e à saúde dos que o habitam, provocadas pela utilização de propriedade vizinha (BRASIL, 2002).
} 
ou qualquer outro motivo de inquietação (LOUREIRO, 2001, p. 131). É preciso lembrar que a perturbação do sossego pode levar a sérias consequências físicas e psicológicas decorrentes da falta de repouso e privação do sono.

Embora o direito ao sossego seja previsto no capítulo sobre os direitos de vizinhança, isto não esvazia o seu conteúdo de direito da personalidade e com oponibilidade erga omnes, ou seja, apesar da sua principal aplicação ser dentro da questão de vizinhança, o direito ao sossego a esta não se limita, podendo ser aplicado em diversas outras situações cujo incômodo por som, cheiro, luz e sensações térmicas extrapole o nível do tolerável.

São exemplos de ofensas ao direito ao sossego: (i) festas noturnas com som alto; (ii) gritarias; (iii) barulho exagerado de indústrias; (iv) emprego de alto-falantes (DINIZ, 2007, p. 267); (v) altos ruídos provocados pelo apartamento superior; (vi) carros com alto- falantes; (vii) disparo de alarmes de veículos e imóveis; (viii) barulho de animais. O que deve ser levado em consideração é a tolerabilidade da utilização da propriedade: se o incômodo não ultrapassar determinado nível, não estará caracterizado ofensa ao sossego.

Ademais, todos têm o direito de repouso e sossego, em especial no período noturno, por isso o Art. 42 da Lei de Contravenções Penais (DecretoLei n. 3.688 de 1941) prevê a contravenção de perturbação do sossego público. ${ }^{10}$

Aqui deve ser levada em consideração a qualidade de vida advinda de um meio ambiente equilibrado, isso no sentido de vida com saúde física e mental (LOUREIRO, 2001, p. 141). Assim, como o direito ao sossego permite a exclusão de impressões sensitivas tais como o som e imagem, a poluição

${ }^{10}$ Art. 42. Perturbar alguém o trabalho ou o sossego alheios: I - com gritaria ou algazarra; II - exercendo profissão incômoda ou ruidosa, em desacordo com as prescrições legais; III abusando de instrumentos sonoros ou sinais acústicos; IV - provocando ou não procurando impedir barulho produzido por animal de que tem a guarda: Pena - prisão simples, de quinze dias a três meses, ou multa, de duzentos mil réis a dois contos de réis (BRASIL, 1941). 
sonora e a poluição visual são ofensas para além do meio ambiente de cunho coletivo, pois incluem prejuízos a esse direito individual da personalidade.

\section{A poluição sonora e dano ao Direito ao Sossego}

Neste ponto já se pode observar que existe uma correlação necessária entre o direito coletivo do meio ambiente e os direitos individuais da personalidade. As dimensões de direitos fundamentais e os direitos da personalidade não são antagônicas ou excludentes, mas se complementam na proteção e promoção do livre desenvolvimento da personalidade e da dignidade da pessoa humana.

Dessa maneira, o direito ao sossego tem uma relação tanto com interesses difusos quanto interesses individuais, principalmente na sociedade urbana crescente em que o sossego domiciliar é um bem necessário para garantia da saúde do ser humano (BLUM, 2011). Por isso os instrumentos de proteção do meio ambiente urbano como o zoneamento e estudo de impacto de vizinhança também são úteis na tutela do direito ao sossego.

O zoneamento urbano consiste em uma organização e ordenação do território das cidades de forma que o exercício de determinadas atividades não prejudique áreas residenciais, evitando inconvenientes. Impede-se que estabelecimentos se instalem pela cidade de forma arbitrária (GUIMARÃES JÚNIOR, 2001).

O estudo de impacto de vizinhança determina que determinados estabelecimentos, assim definidos em lei municipal, deverão estudar os efeitos positivos e negativos que uma nova construção e o exercício de determinada atividade podem causar na vizinhança antes de obter a licença ou autorização para construção. Isto fornecerá os elementos necessários para avaliar quais são os direitos e obrigações do proprietário para com seus vizinhos (GUIMARÃES JÚNIOR, 2001). 
Esses dois instrumentos podem ser utilizados para evitar que a poluição sonora venha a ocorrer, privilegiando o princípio ambiental de prevenção ao dano. Em caso de consumação da poluição sonora, o tratamento deve ser aquele repressivo de reparação do dano ambiental causado. Contudo, o dano causado pela poluição sonora também pode ser reflexo e interferir na esfera individual do cidadão, causando lesão ao direito ao sossego. Neste caso o tratamento também deverá ser repressivo por meio da compensação por danos morais.

Verificada a ineficiência do poder público no controle das atividades poluidoras, dentre elas a sonora, cabe ao lesado o acionamento do Poder Judiciário. Acrescenta-se que mesmo se as autoridades entenderem que o estabelecimento não infringe as normas ambientais, o vizinho poderá levar ao judiciário sua pretensão de fazer cessar o incômodo causado pelo excesso de ruídos (ATHENIENESE, 2011, p. 3).

Por se tratar de lesão a direito da personalidade, a violação do direito ao sossego deve ser compensada pela fixação dos danos morais de acordo com a extensão do dano causado. Para isto pode ser levado em consideração critérios como a dimensão - pequena, média, grande - e a sua duração curto, médio ou longo prazo (MORAES, 2007).

Em se tratando de poluição sonora a fixação do dano moral deve observar, portanto, a dimensão do volume da perturbação bem como o tempo de sua duração. O dano causado por um show durante uma noite não pode gerar a mesma indenização de uma boate cujo som viola o sossego da pessoa de forma sistemática.

\section{Conclusão}

O trabalho teve como propósito analisar as consequências jurídicas da poluição sonora para o meio ambiente e para o direito ao sossego, cuja violação ocorre com frequência nas cidades. Neste sentido, demonstrou-se 
que esses ruídos que afetam o bem-estar e a qualidade de vida são considerados danos ambientais coletivos e individuais, interferindo na dignidade da pessoa humana, merecendo desta forma, a proteção legal e das autoridades.

Para tanto, mostrou-se a impossibilidade do estudo dissociado entre meio ambiente e o ser humano, em especial visto o reconhecimento da dignidade da pessoa humana pela Constituição Federal, tratado como elemento central do ordenamento jurídico, sendo que para sua efetivação também se faz necessário um ambiente sadio "para as presentes e futuras gerações".

Como visto, a poluição sonora consiste em dano ambiental, pois o meio ambiente, inclusive com amparo constitucional, abrange o meio ambiente cultural, o artificial, o do trabalho, o natural e o patrimônio genético. Notouse que o dano ambiental provocado por poluição sonora pode lesar interesses individuais, individuais homogêneos, coletivos ou difusos. Neste sentido, fazse indispensável a presença e a atuação do poder público para controlar as atividades poluidoras, em alguns casos, por via de atos de consentimento, permitindo que a atividade seja exercida somente nas condições estabelecidas, e em todos casos, exercendo fiscalização efetiva das condutas indevidas que afetem o direito ao sossego. Não obstante, o controle dessas atividades deverá ser realizado especialmente pelo Poder Executivo no exercício do poder de polícia, que não afasta aquele lesado de procurar tutela jurisdicional individual ou ainda, por via do Ministério Público.

Destacou-se que o direito ao sossego indica um estado de paz de espírito ligado à tranquilidade, à ausência de perturbação, ao descanso e à proteção de sua integridade física e psíquica. Desta forma o direito ao sossego determina o dever erga omnes de manter um ambiente sadio e propício para o livre desenvolvimento da personalidade do ser humano, respeitando as suas decisões no tocante às impressões sensitivas que a pessoa deseja ou não compartilhar. 


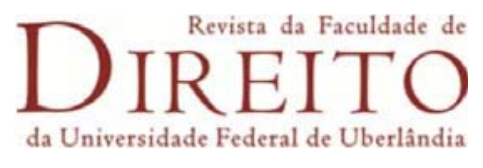

Além da relação íntima do direito ao sossego com os direitos da personalidade humana que garantem a dignidade da pessoa humana, tal proteção encontra amparo também no direito de vizinhança, previsto no Art. 1.277 do Código Civil, que sintetiza que o sossego do vizinho não pode ser prejudicado não apenas pelo barulho (som), mas também pelo cheiro, luz ou qualquer outro motivo de inquietação, bem como a previsão que sua violação implica na tipificação de Contravenção Penal, conforme previsto no Art. 42 do Decreto Lei n. 3.688.

Por último, a fim de efetivar a proteção à dignidade da pessoa humana, o livre desenvolvimento da personalidade humana, o direito ao sossego e ao meio ambiente sadio e de qualidade, constata-se que são imperiosas ações eficazes por parte das autoridades públicas, seja por via de medidas preventivas, como as licenças, autorizações, zoneamento e o estudo de impacto de vizinhança, bem como a atuação do Ministério Público na repressão das condutas atentatórios às garantias acima estabelecidas. De forma individual, a pessoa lesada ainda poderá recorrer ao Poder Judiciário em busca de indenização por danos morais que deverá ser arbitrado levando em consideração a sua dimensão e duração.

\section{Referências}

ALEMAR, Aguinaldo. Direito e ambientalismo: fundamentos para o estudo do direito ambiental. Belo Horizonte: Arrais, 2013.

ALONSO Jr., Hamilton. Direito fundamental ao meio ambiente e ações coletivas. São Paulo: Revista dos Tribunais, 2006.

ALTO, Lívia Tognolo da Silva Monte. A proteção dos direitos de personalidade nas relações de vizinhança: direito à intimidade e vida privada e direito ao sossego. In: MIRANDA, Jorge; RODRIGUES JR., Otavio Luiz; FRUET, Gustavo Bonato. Direitos da Personalidade. São Paulo: Atlas, 2012.

ANDRADE, José Vieira de. Os direitos fundamentais na constituição portuguesa de 1976. $5^{\text {a }}$ ed. Coimbra: Almedina, 2012.

ANTUNES, Paulo de Bessa. Direito ambiental. 12 ed. Rio de Janeiro: Lumen Juris, 2010. ASCENSÃO, José de Oliveira. Direito civil: teoria geral, vol. 1. $2^{\mathrm{a}}$ ed. Coimbra: Coimbra, 2000.

ATHENIENSE, Aristóteles. Legitimidade e Conveniência da Repressão Judicial à Poluição Sonora. In: MILARÉ, Édis; MACHADO, Paulo Affonso Leme. Doutrinas essenciais - 


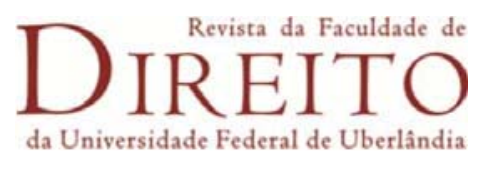

direito ambiental: Vol. II - conservação e degradação do meio ambiente. São Paulo: Revista dos Tribunais, 2011.

BLUM, Rita Peixoto Ferreira. O direito de vizinhança e sua correlação com os interesses difusos e coletivos. Revista de Direito Imobiliário, vol. 70, p. 225-242. São Paulo, jan.jun., 2011.

BONAVIDES, Paulo. Curso de direito constitucional. 5. ed. São Paulo: Malheiros, 1994.

BRASIL. Constituição Federal de 1988. Brasília, DF, 5 out. 1988.

Lei Federal n. 10.406 de 10 de janeiro de 2002. Institui o Código Civil. Brasília, DF, 2002.

Decreto. 591 de 6 de julho de 1992. Promulga o Pacto Internacional sobre Direitos Econômicos, Sociais e Culturais de 1966. Brasília, DF, 1992

Decreto -Lei n. 3.688 de 3 de outubro de 1941. Institui a Lei das Contravensões Penais. Rio de janeiro, RJ, 1941.

Lei Federal n. 8.938 de 31 de agosto de 1981. Regulamento Mensagem de veto (Vide Decreto de 15 de setembro de 2010) Dispõe sobre a Política Nacional do Meio Ambiente, seus fins e mecanismos de formulação e aplicação, e dá outras providências. Brasília, DF, 1981.

Supremo Tribunal Federal. Mandado de Segurança n. ${ }^{\circ}$ 22.164-0/SP. Relator Min. Celso de Mello. Julgamento em: 30 out. 1995. Publicado em: 17 nov. 1995.

CANARIS, Claus-Wilhem. Pensamento sistemático e conceito de sistema na ciência do direito. Lisboa: Fundação Calouste Gulbenkian, 2008.

CANOTILHO, J. J. Gomes. Direito constitucional e teoria da constituição. $7^{a}$ ed. Coimbra: Almedina, 2003.

CANTALI, Fernanda Borghetti. Direitos da personalidade: disponibilidade relativa, autonomia privada e dignidade humana. Porto Alegre: Livraria do Advogado, 2009.

COMPARATO, Fábio Konder. A afirmação histórica dos direitos humanos. 2. ed. São Paulo: Saraiva, 2001.

CUPIS, Adriano de. Os direitos da personalidade. São Paulo: Quorum, 2008.

DINIZ, Maria Helena. Compêndio de introdução à ciência do direito. São Paulo: Saraiva, 2009.

DINIZ, Maria Helena. Curso de direito civil brasileiro: direito das coisas. São Paulo: Saraiva, 2007.

FINK, Daniel Roberto. A poluição sonora e o Ministério Público. In: MILARÉ, Édis; MACHADO, Paulo Affonso Leme. Doutrinas essenciais - direito ambiental: Vol. 13 conservação e degradação do meio ambiente. São Paulo: Revista dos Tribunais, 1999.

FIORILlO, Celso Antonio Pacheco. Princípios do direito processual ambiental. 2 ed. São Paulo: Saraiva, 2007.

FRANGETTO, Flavia Witkowski. O direito à qualidade sonora. In: MILARÉ, Édis; MACHADO, Paulo Affonso Leme. Doutrinas essenciais - direito ambiental: Vol. II conservação e degradação do meio ambiente. São Paulo: Revista dos Tribunais, 2011.

GARCIA, Enéas Costa. Direito geral da personalidade no sistema jurídico brasileiro. São Paulo: Juarez de Oliveira, 2007.

GOMES, Orlando. Introdução ao direito civil. $4^{\text {a }}$ ed. Rio de Janeiro: Forense, 1974. 


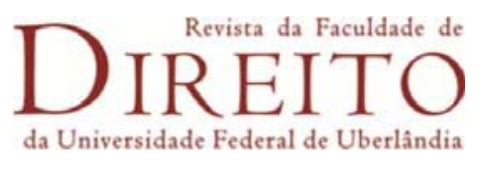

LARENZ, Karl. Metodologia da ciência do direito. Lisboa: Fundação Calouste Gulbenkian, 2009.

LEFF, Enrique. Saber ambiental: sustentabilidade, racionalidade, complexidade, poder. Petrópolis: Vozes, 2012.

LEITE, José Rubens Morato; AYALA, Patryck de Araújo. Dano ambiental: do individual ao coletivo extrapatrimonial. 4. ed. São Paulo: Revista dos Tribunais, 2011.

LORENZETTI, Ricardo Luis. Teoria geral do direito ambiental. São Paulo: Revista dos Tribunais, 2010.

LOUREIRO, Francisco Eduardo. Direito ao sossego. In.: LOTUFO, Renan (coord.). Cadernos de autonomia privada: Vol. 2. Curitiba: Juruá, 2001.

MARINELA, Fernanda. Direito Administrativo. 11 ed. São Paulo: Saraiva, 2017.

MARTINS, Leonardo. Liberdade e igualdade. In: __. Liberdade e estado constitucional: Leitura jurídico-dogmática de uma complexa relação a partir da teoria liberal dos direitos fundamentais. São Paulo: Atlas, 2012.

MILARÉ, Édis. Direito do ambiente: a gestão ambiental em foco. 6. ed. São Paulo: Revista dos Tribunais, 2009.

MORAES, Maria Celina Bodin de. Danos à pessoa humana: uma leitura civilconstitucional dos danos morais. Rio de Janeiro: Renovar, 2007.

PIEROTH, Bodo; SCHLINK, Bernhard. Direitos fundamentais. São Paulo: Saraiva, 2012.

PINTO, Carlos Alberto da Mota. Teoria geral do direito civil. 3 ed. Coimbra: Coimbra, 1999.

RÁO, Vicente. O direito e a vida dos direitos. v. 2, 4. ed. São Paulo: Revista dos Tribunais, 1997.

RIBEIRO,

SARLET, Ingo Wolfgang. A eficácia dos direitos fundamentais: uma teoria geral dos direitos fundamentais na perspectiva constitucional. $11^{\mathrm{a}}$ ed. Porto Alegre: Livraria do Advogado, 2012.

SILVA, José Afonso da. Direito Ambiental Constitucional. 7. ed. São Paulo: Malheiros, 2009.

TEPEDINO, Gustavo. A tutela da personalidade no ordenamento civil-constitucional brasileiro. In: Temas de direito civil. Rio de Janeiro: Renovar, 2008.

ZANINI, Leonardo Estevam de Assis. Direitos da personalidade. São Paulo: Saraiva, 2011.

Artigo recebido em: 21/07/2019.

Aceito para publicação em: 26/02/2020. 